\title{
Renovation of industrial areas, taking into account the determination of residual deformations of existing production facilities
}

\author{
Tatiana Zolina ${ }^{1 *}$, and Tatiana Tsitman ${ }^{1}$ \\ ${ }^{1}$ Astrakhan State Architectural And Construction University, 414056, 18 Tatishcheva str., Astrakhan, \\ Russia
}

\begin{abstract}
The article presents the possibilities of integrated approach to the renovation of industrial areas, considering architectural and planning concepts, new functions and carrying out structural surveys of existing industrial buildings. The feasibility of industrial facilities renovation, the introduction of new functions required by certain areas of the city lead to the economic, social, cultural, psychological and aesthetic development of the areas. Nowadays the development trends of large cities are such that industrial enterprises are moved outside the city center or even the city. Furthermore adverse environmental effects are significantly reduced in the city. Methods of adapting production facilities to new functions are determined. Definitions of residual load-bearing capacities of production shops building structures and design features, as well as deformations identified during operation, are formed.
\end{abstract}

\section{Introduction}

The development of modern cities includes the introduction of industrial areas into the urban environment, which, within the city expanding, turned out to be in the central part of the city. This approach allows to use reserve areas for the development of public spaces or for residential development, to improve the city environment, and to create additional attracting places for citizens [1].The historical change of cities developed in such a way that gradually industrial areas remained in the central part of the city, surrounded by residential buildings. Currently, in many cities, such territories are either abandoned or partially used [2]. Their introduction into the modern fabric of the city with a new function is one of the main tasks in urban planning decisions of cities. Examples of such decisions may be Moscow and St. Petersburg. Architectural decisions of such places as "Red October", "Flacon", "Hlebozavod" in Moscow and "New Holland" in St. Petersburg, clearly show how such solutions enrich the urban environment (Fig.1, 2).

\footnotetext{
${ }^{*}$ Corresponding author: zolinatv@yandex.ru
} 

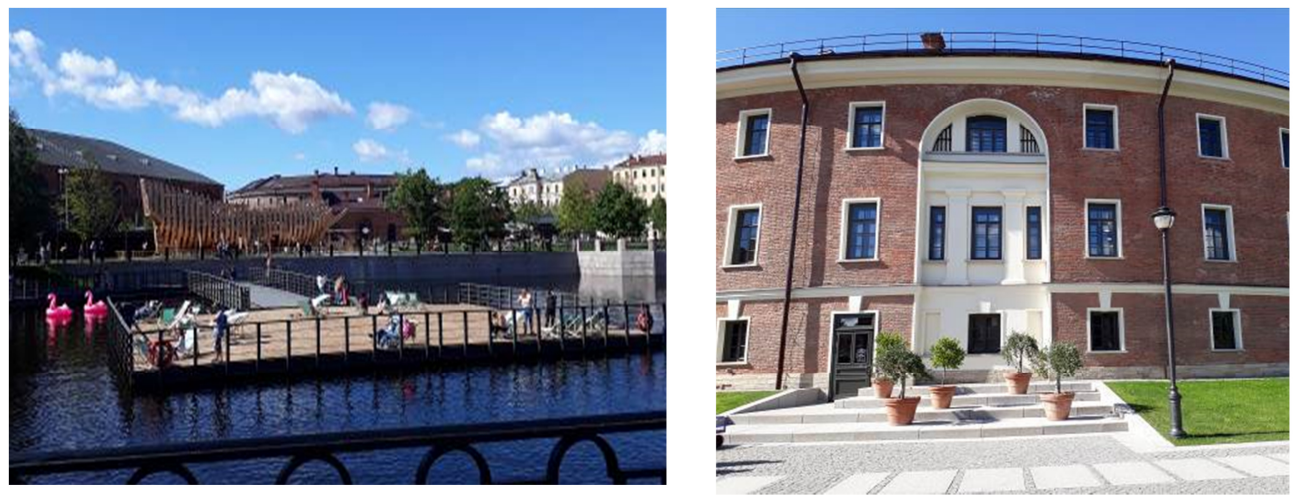

Fig. 1. "New Holland" in St. Petersburg.
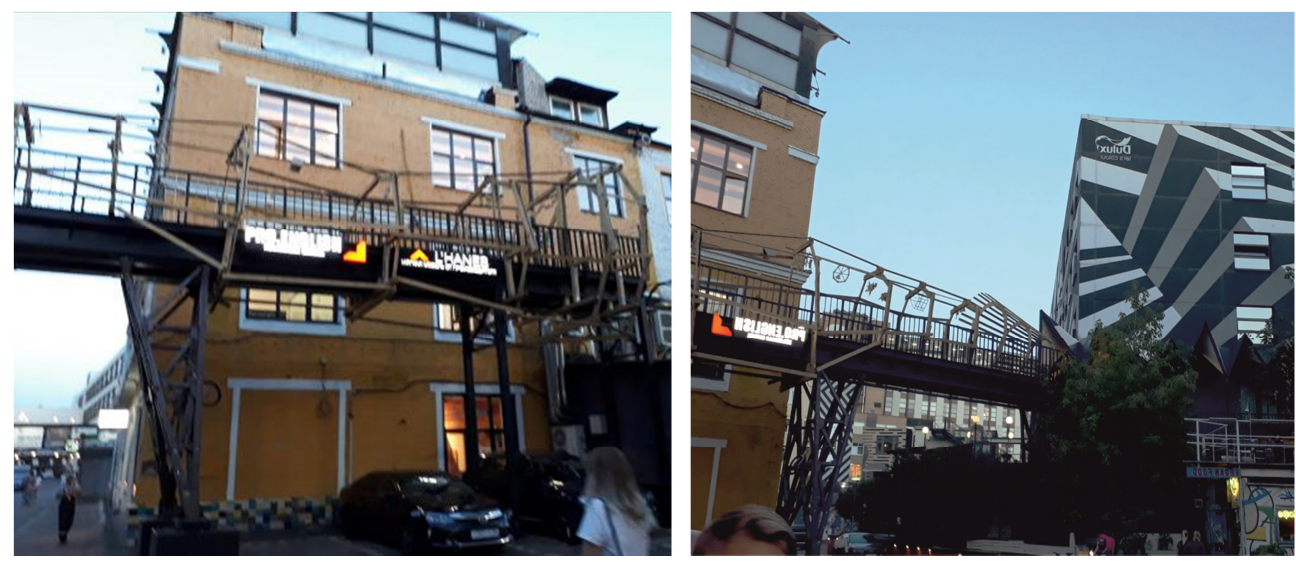

Fig. 2. Moscow.

This issue is relevant in Astrakhan too. While city development some territories of industrial facilities have remained in the center, on the embankments, in residential buildings. Using these areas gives a lot of advantages: large areas providing to create a modern and comfortable environment transport and pedestrian accessibility, current infrastructure and engineering supportx [3,4]. The removal of production areas from the central part of the city allows improving ecological environment, which is also relevant.

Currently there are a lot of researches on the renovation of production areas. The adaptation of industrial enterprises was also considered in studies published by the authors $[5,6]$. Moreover, the article considers the structures located at the places. About 20 production facilities located in the city limits have been preserved in Astrakhan. According to the Astrakhan planned development, it is planned to liquidate a number of industrial facilities located in the central part of the city, as well as part of the production zone along the Volga by 2025 [7] Turned available building areas can become main centers for the development of science, art, sports, etc.(Fig.3) 


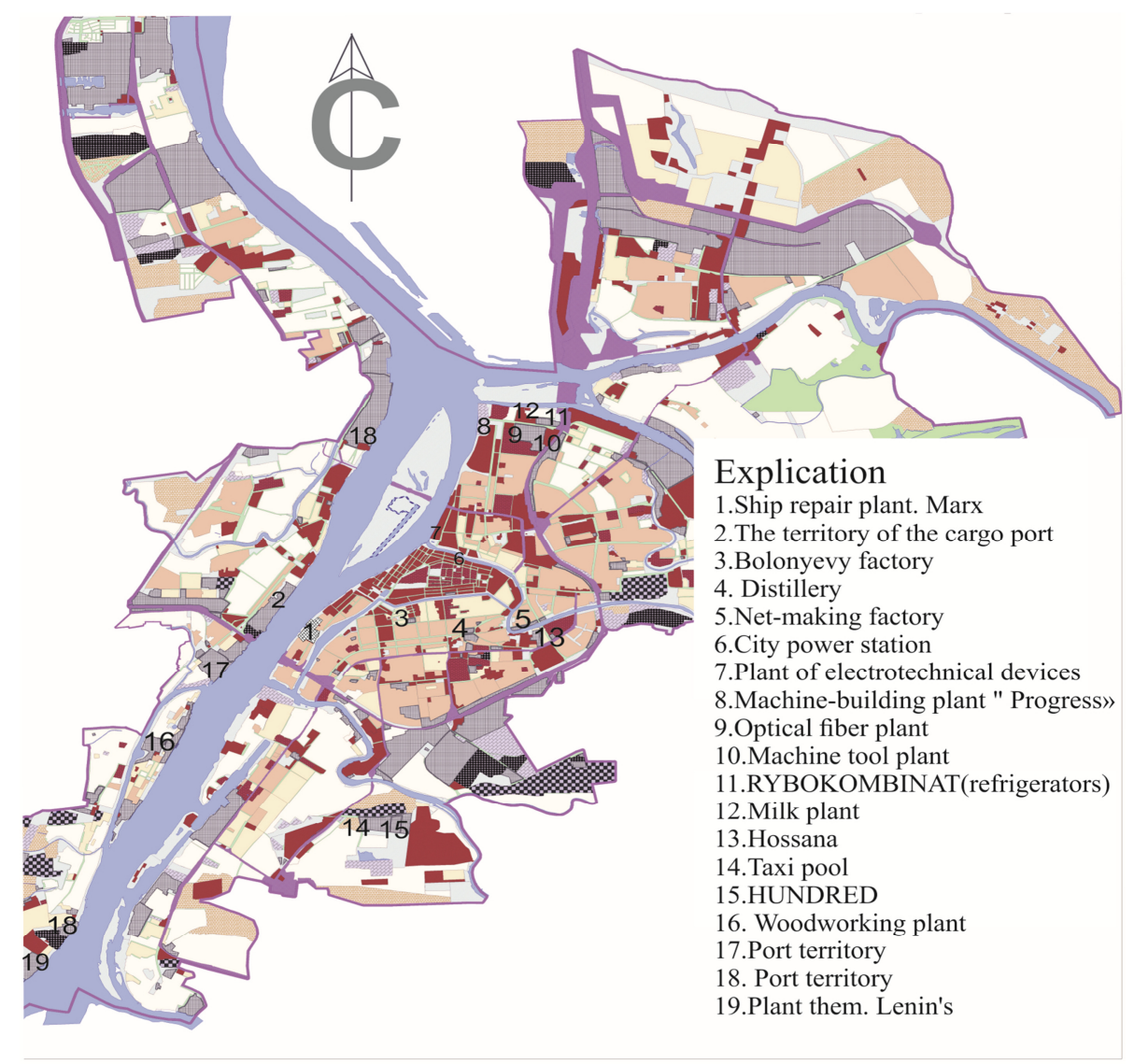

Fig. 3. Location of production territories in Astrakhan.

\section{Materials and methods}

Renovation of number of them has already been considered and options of functionality have been proposed. The capabilities of the territory and objects located on them were considered before the design. Currently, about 45 objects are located in the designed territory of the plant.

1. 7 workshops with technical equipment;

2. 13 administrative and utility buildings;

3. 20 buildings of temporary use;

4. 5 platforms.

The proposed new functional purpose of the territory is a multifunctional park, which has a recreational load of 282 people and belongs to the first category of parks, so a high level of landscaping, a dense network of pedestrian alleys and a large number of park structures should be provided.

After the current urban planning situation has been analyzed and the main groups of functions in the territory have been assigned, it is necessary to reason out a high-quality renovation plan, which will form the basis of the new urban planning scheme for the territory $[8,9]$. The workshops recently began to be built should be demolished and arranged them as recreational zones. Those current simple clean designed structures have already existed should be renovated and redesigned for relevant public function for them, 
filling the needs of citizens, both in the district and in the city as a whole. Thus, a number of the following proposals are formed: (Fig. 4)

1. to transform and improve the entrance to car entry;

2. to leave the administrative building (object No. 2), only giving the structure new architectural features;

3. to unite two workshops, namely, a mechanical workshop (object No. 10) and a mechanical workshop, a boiler room (object No. 13), thereby forming a museum and exhibition complex;

4. to repair all household buildings except workshop No. 12 and to make new administrative buildings from buildings No. 6 and No. 7, and to make large warehouses from buildings No. 3 and No. 4;

5. to turn the shipbuilding workshop (object No. 8) into a large greenhouse complex with winter gardens;

6. to arrange the fitting and assembly workshop (object No. 5) convert into a huge public place with the library, Internet cafes and various spaces of the cultural and educational sphere;

7. to convert the diesel workshop (object No. 15) into an art and hobby space to gather people together by the same hobby or interest to art;

8. to turn objects No. 16 and No. 17 to water treatment facilities;

9. to improve and transform platform No. 11 into a stage directly connected with the amphitheater;

10. to make an exhibition area from the floating dock object No. 18;

11. to adapt an object located between two mechanical workshops to food services area (Fig.4, 5).

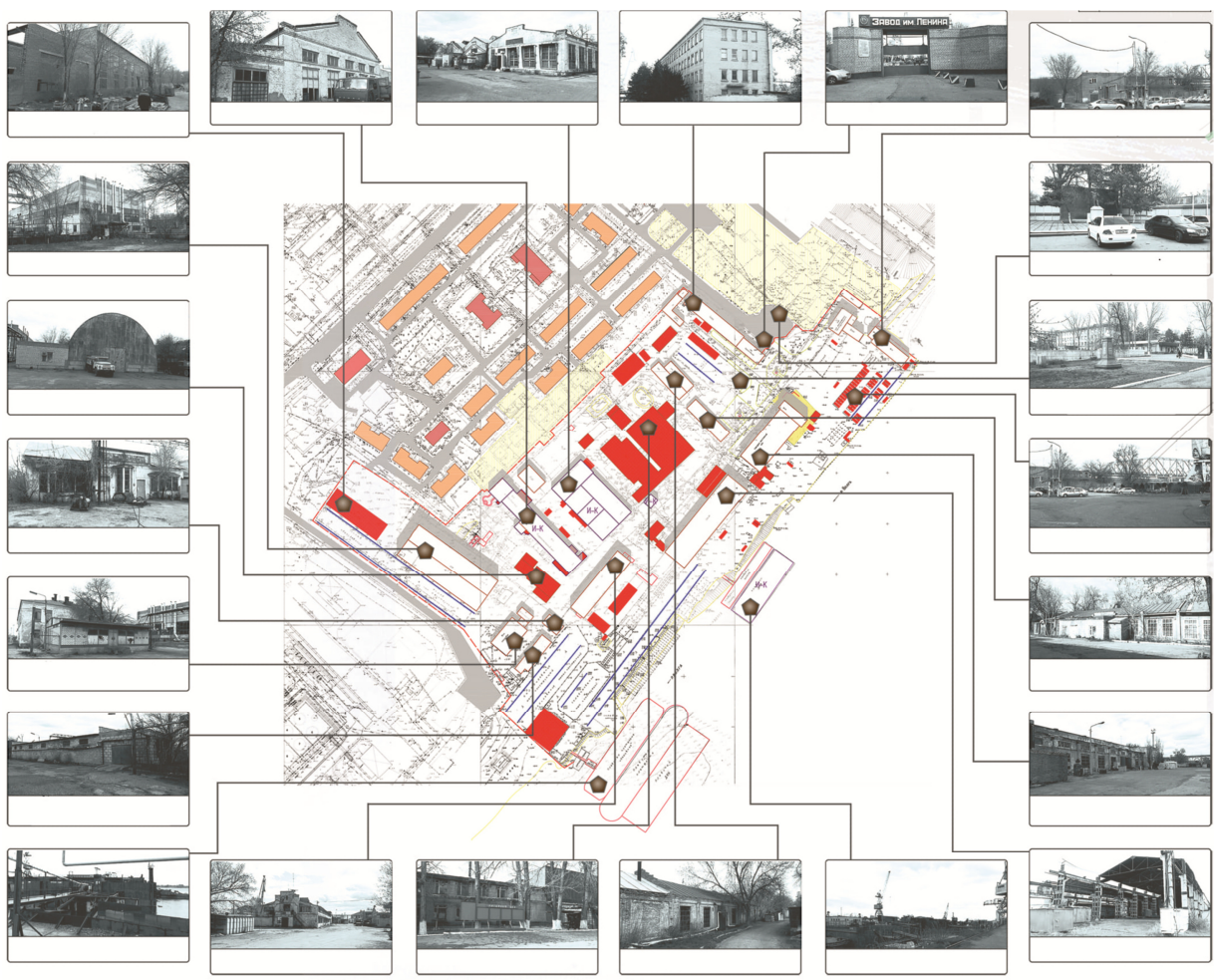

Fig. 4. Plant named after Lenin renovation scheme in Astrakhan. 


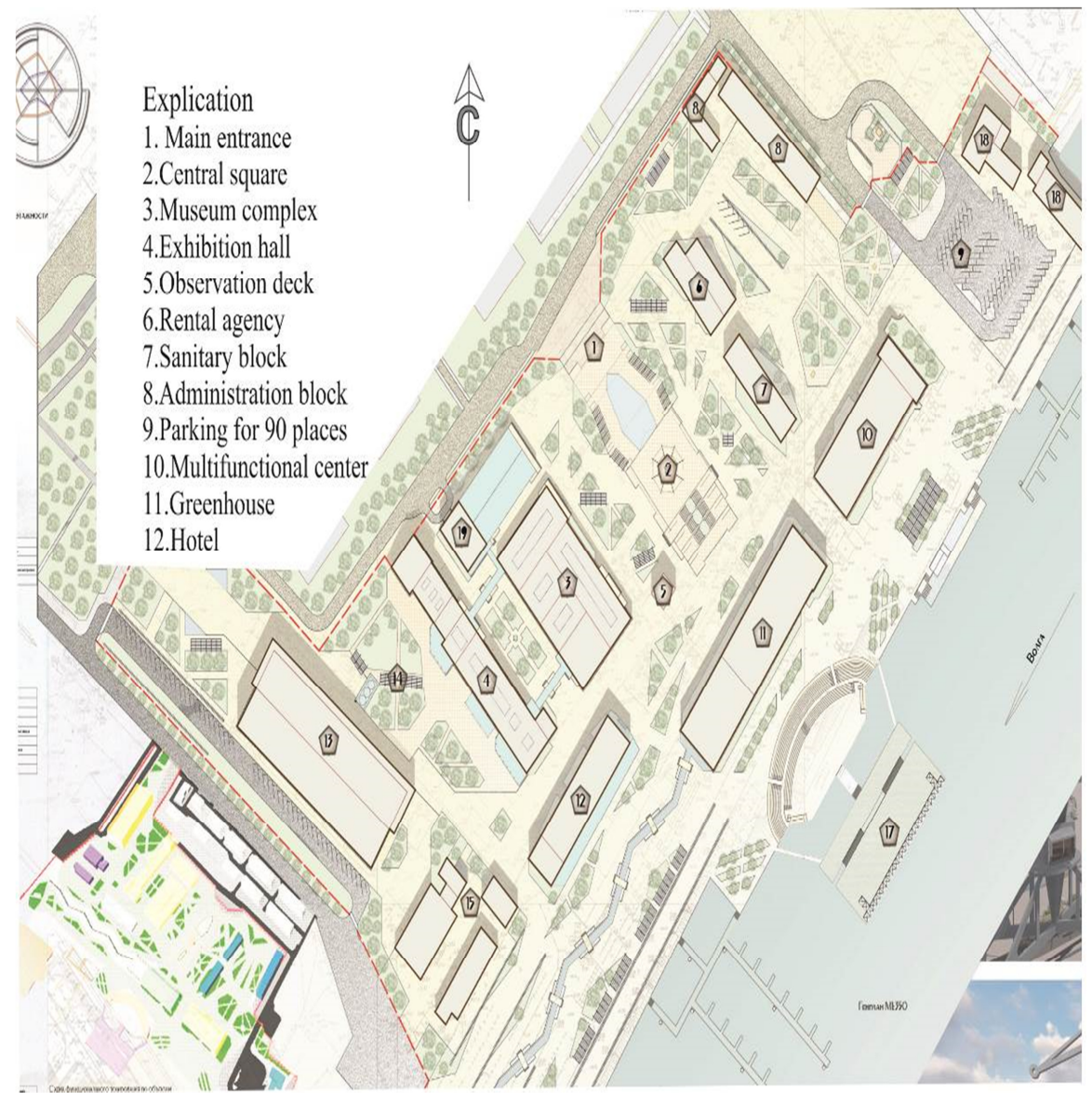

Fig. 5. Facades of the production workshop of the plant. Lenin, adapted to the public function.

The plant is surrounded by residential buildings and completely blocks people from access to the embankment. Production is not fully operational and is in an abandoned state. The project proposal considered the possibility of its renovation under the public space, the development of a new embankment, the creation of zones of quiet and active recreation. Moreover, the buildings located on the territory also adapt to the public functions: museums, auditoriums, exhibition spaces, cafes, workshops, etc [10].

There is one more issue in the renovation of industrial facilities: technical inspection of buildings and assessment of their possible use for a new function, determination of the residual safety factor.

Each object must be inspected, it is necessary to perform dimensional drawings, conduct research on residual deformation and residual bearing capacity. Decisions on the renovation of facilities will be made based on the conducted surveys. Usually these are office buildings and production halls, as well as storage facilities [11].

Adaptation of the administrative building does not cause troubles, because these buildings are usually in good condition, and these were intended for permanent residence of people. Also within the adaptation these buildings remain administrative buildings [12].

Much more complicated is to renovate production workshops. Each building is unique both in appearance and in structural design. Besides, used structures are of the greatest interest to the preservation and formation of the loft style (Fig. 6). 

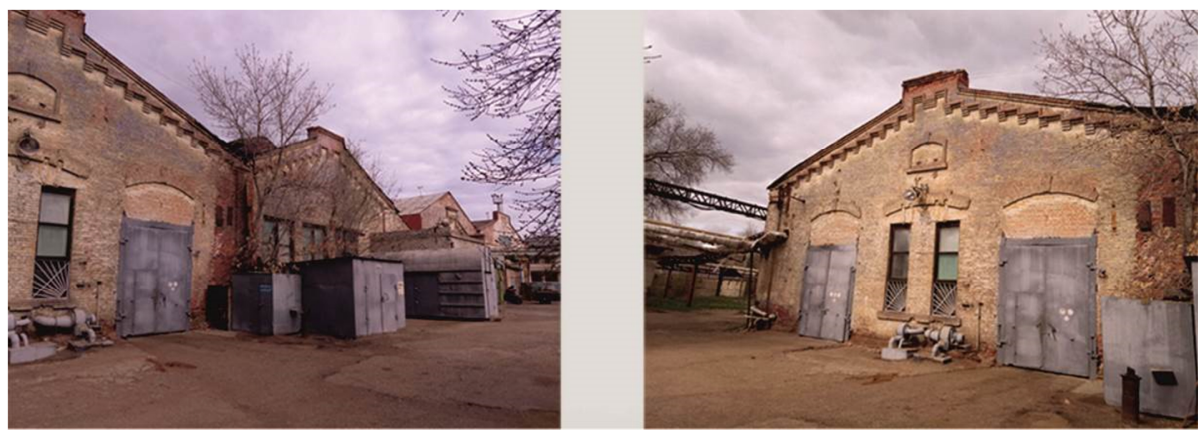

Fig. 6. Photofixation of the industrial building of the plant of Lenin in Astrakhan.

\section{Results}

There are several methods for renovating production facilities in public buildings [13]:

1. "Applique" method, based on the creation of a new facade composition, based on an already existing structural system;

2. Method of the analogs, expecting comparison with similar objects and the analogy between the functional purpose and object images and architectural details;

3. Method of the integration - the introduction of new structures and elements into an existing object in order to enhance the visual perception of an architectural object and adapt it to a new purpose and surrounding development. This method allows you to add new active dominants to the urban planning situation (Fig.7).

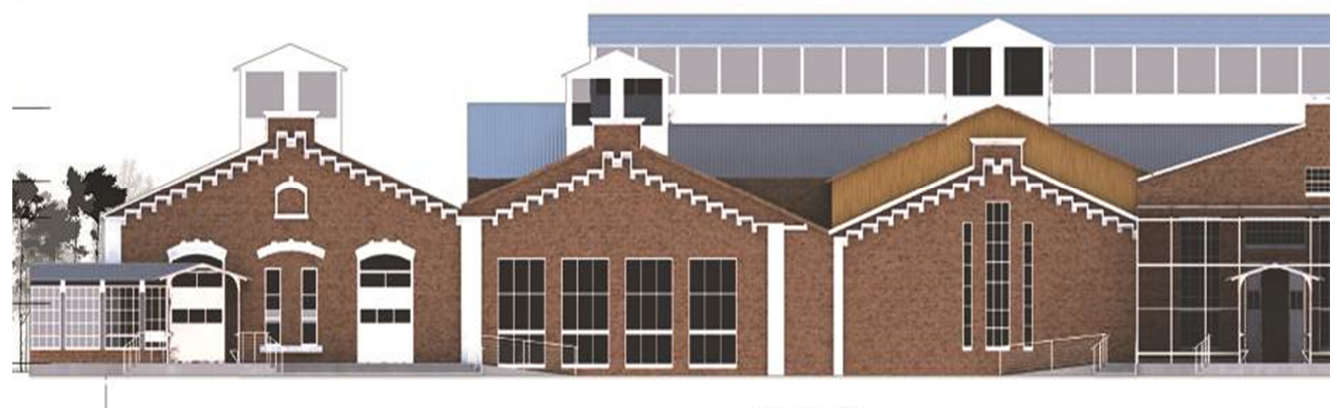

Fig. 7. Facades of the production workshop of the plant. Lenin, adapted to the public function.

To adapt industrial zones to modern conditions and their favorable relationship with nearing objects in the structure of the urban environment, the following techniques are distinguished (Fig.8):

1. Modification - involves changing the shape, configuration or proportions of the whole object, as well as its individual parts;

2. Replacement - the introduction of new forms, designs, materials, etc. instead of the old;

3. Removal or addition - to change the number of forms, structures, functions, with the ability to connect new;

4. Conjunction- the combination of ideas, properties, functional components, elements of object between themselves; 
5. Inversion - consideration of the problem from the contrary with the possibility of turning over.

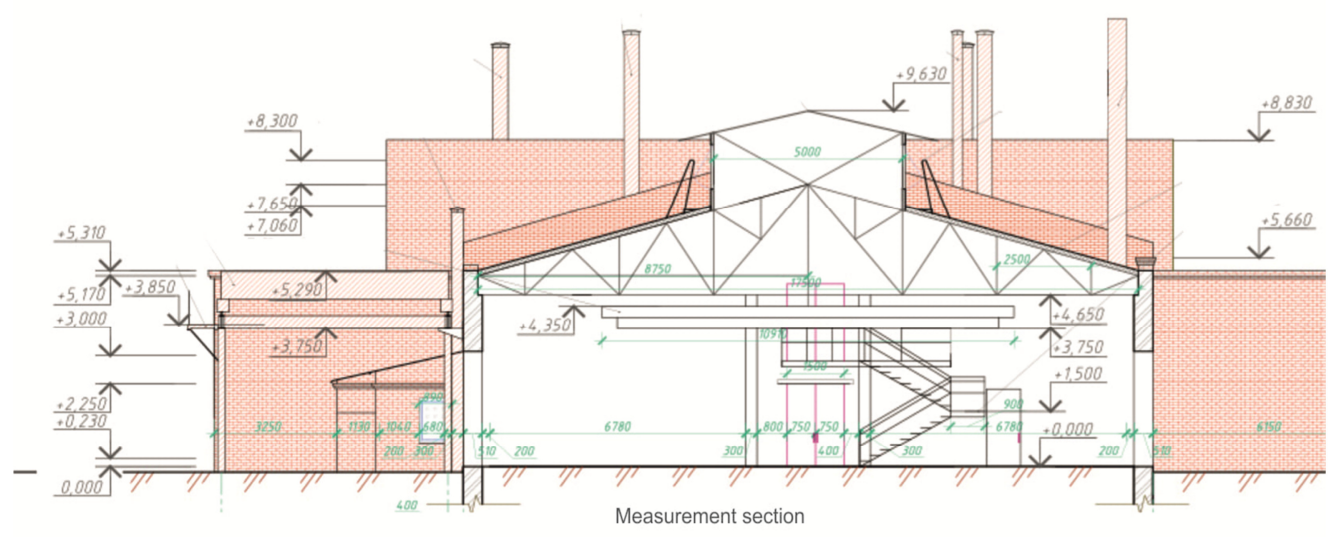

Fig. 8. Measured facade and section with the design features of the object. Plant of Lenin in Astrakhan.

One of the main issues at such facilities is a significant decrease in their bearing capacity during operation. In the case of buildings and structures for production purposes, under discussion decrease is caused by the accumulation of defects and an increase in displacements at the nodal points of the frame under the influence of various combinations of loads like technogenic or natural formations [14].

Current practice assess residual service life mainly is based on a deterministic approach that is associated with the necessity of technical surveys of the building at a specific time. The corresponding algorithm is reduced to assessing the margin of safety, based on a comparison of the results of verification calculation of the actual characteristics of the stress-strain state obtained during the inspection of the building, with the corresponding standard values.

However, deterministic methods only partially satisfy the requirements for the degree of reliability of the results obtained, since; for example, they do not take into account the dynamics of changes in the physical parameters of materials and the static circuit due to corrosion of metal structures and destruction of bolted joints.

The accidental nature of the change in time of the stiffness characteristics of the elements of the supporting structures, as well as the duration and direction of the disturbing influences, initially involves the determination of the time period for the safe operation of the building in the probabilistic direction. The limited scope of available statistical information about the change of properties of the object of research in this case can be eliminated by solving the task at the level of correlation with the building of related regression dependencies between model parameters. In this situation, the problem of estimating the residual life becomes particularly relevant, since its solution allows predicting the kinetics of changes in the stress-strain state taking into account defects that occur during the operation of the technical system and determining the time of its maintainability. Timeliness of the necessary work to restore the identified structural elements with a high degree of accumulated deformations can lead to a significant extension of the term of further operation of the facility as a whole and will allow adapting it to a new function.

However, the method of predicting the resource of a building, as the most appropriate for the random nature of the impacts, has still not found wide application in engineering practice. This fact is primarily associated with the lack of a sufficient number of developed 
methodic of probabilistic calculation and computational complexity nature, especially for spatial models of buildings and structures. At the same time, there is no generalized methodology for assessing the dynamics of the decrease in the bearing construction during its operation, which allows us to make a forecast about the development of the situation in future periods, and therefore, even in the case of using modern diagnostic tools, the expected effect is not achievedx [2].

\section{Deliberation}

Thus, the relevance of the research of objects on the renovation territory is to maintain and ensure trouble-free operation of industrial buildings in a new function with a significant reduction in the intensity of their surveys and increase the attractiveness of investments in the modernization and adaptation of buildings, which is of great socio-economic importance for the city.

The practical value of the research of former industrial buildings is that it allows:

1. to track the kinetics of changes in the stiffness characteristics of the frame elements of a particular industrial building, depending on the accumulation of damage during operation;

2. to predict a change in the building's resistance to external and internal influences after a retention period of operation of the building on the basis of the derived regression dependencies;

3. to predict the occurrence and degree of consequences of possible emergency situations and the timely adoption of measures to prevent them;

4. Prepare an expert opinion with the provision of analytical information on the reasons for the situation prevailing at the facility.

5. Implementation of the developed algorithms allows you to get results for each specific object and analyze the operation of the building under the action of both static and dynamic load, which becomes possible thanks to the developed software package. Developed by one of the authors of a software tool for the computer acts as a tool to automate the calculation, analysis and prediction of performance change the building structure and the timing of further secure its operation, providing a convenient interface for organizing and conducting data processing, obtained during examination of the object.

The developed theoretical provisions were confirmed in numerous field tests of industrial buildings with crane equipment and were effectively used in the development of recommendations for strengthening the designs of the surveyed workshops, which allowed introducing a new function to the objects under consideration and increasing the period of their trouble-free operation [15].

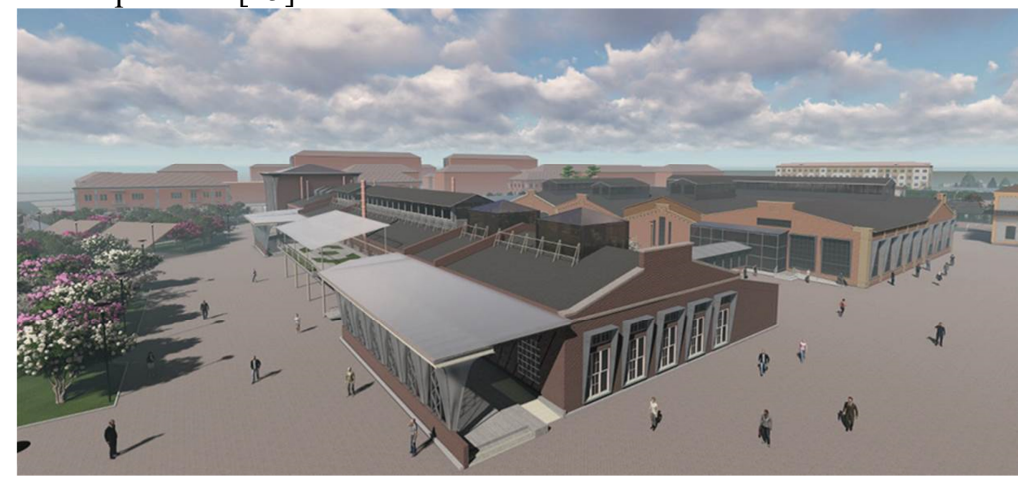

Fig 9. The proposal for the renovation of the plant of Lenin in Astrakhan. Perspective view. 


\section{Conclusion}

Thus, joint work in solving architectural, planning and structural problems will allow returning valuable territories and buildings to the urban environment, creating new public spaces for citizens meeting modern requirements, both architecturally and from the point of view of safety in further operation (Fig 9). The return of industrial areas and production buildings to the city with new, necessary public functions will create an improvement in both the social and environmental components.

\section{References}

1. R. A. Drozhzhin,. Bull. Sib. St. Ind.Un. 1 (11) (2015)

2. E. Koneva, New life to dead neighborhoods, URL: http://expert.ru/2011/08/2/novayazhizn-mertvyih-kvartalov (reference date: 20.08.2019).

3. M. Andreev, Renovation of industrial areas and facilities. URL: http://archgrafika.ru/publ/bez_kategorij/bez_kategorij/renovacija_promyshlennykh_territorij_i_o bektov/12-1-0-69/ (25.08.2019)

4. R. A. Drozhzhin, ,. Bull. Sib. St. Ind.Un. 1 (11) 2015

5. T. O. Tsitman, V. A. Bogatyreva, Engin. Bull. Casp.: Sci-Tech. J. 4 (14), 29-35 (2015)

6. T. O. Tsitman, V. A., Bogatyrev, A. I. Krapchatov, Civil Engin. Bull. Casp. Sea: Sci Tech J. 1-2 (15-16), 35-45 (2016)

7. Historical information of the plant near ACPP it was. archive.astrobl.ru/afao/8/\%D0\%A0-\%203851

8. T. V. Zolina, P. N. Sadchikov, Advances in Energy, Environment and Materials Science Proceedings of the International Conference on Energy, Environment and Materials Science (EEMS 2015), DOI: 10.1201/b19635-154

9. T. V. Zolina, P. N. Sadchikov, App. Mech. Mater. 752-753, 1218-1223 (2015) DOI: 10.4028 .

10. T. V. Zolina, Sci. Her. Voron. St. Univ. Archit. Civ. Engin. Constr. Archit. 4, 7-15 (2015) ISSN: 2075-0811.

11. T. V. Zolina, App. Mech. Mater. 875, 122-127 (2018)

12. T. V. Zolina, P. N. Sadchikov,Magaz. Civ. Engin. 84(8), 150-161 (2018) DOI: 10.18720/MCE.84.15.

13. M. Andreev, Renovation of industrial areas and facilities, http://archgrafika.ru/publ/bez_kategoriju/bez_kategorij/renovacija_promyshlennykh_territorij_i_ obektov/12-1-0-69/ (дата обращения: 25.08.2019).

14. E. V. Demidova, Acad. Bull. Ural Sri Proj. Raabs, 1, 2013

15. T. V. Zolina, P. N. Sadchikov, Vestnik VolgGASU. Ser.: Constr. Archit. 33(52), 51-56 (2013) 